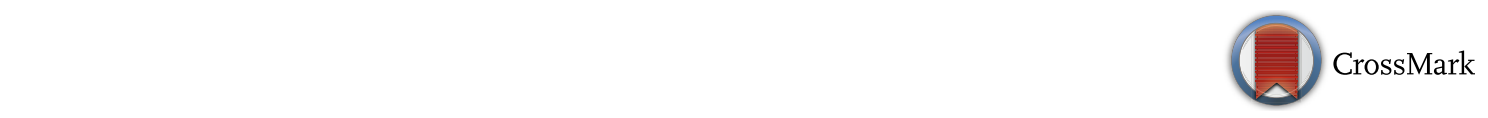

\title{
Interferometric Water Level Tilt Meter Development in Finland and Comparison with Combined Earth Tide and Ocean Loading Models
}

\author{
Hannu Ruotsalainen ${ }^{1}$
}

\begin{abstract}
A modern third-generation interferometric water level tilt meter was developed at the Finnish Geodetic Institute in 2000. The tilt meter has absolute scale and can do high-precision tilt measurements on earth tides, ocean tide loading and atmospheric loading. Additionally, it can be applied in various kinds of geodynamic and geophysical research. The principles and results of the historical 100-year-old Michelson-Gale tilt meter, as well as the development of interferometric water tube tilt meters of the Finnish Geodetic Institute, Finland, are reviewed. Modern Earth tide model tilt combined with Schwiderski ocean tide loading model explains the uncertainty in historical tilt observations by Michelson and Gale. Earth tide tilt observations in Lohja2 geodynamic station, southern Finland, are compared with the combined model earth tide and four ocean tide loading models. The observed diurnal and semidiurnal harmonic constituents do not fit well with combined models. The reason could be a result of the improper harmonic modelling of the Baltic Sea tides in those models.
\end{abstract}

Key words: Interferometric tilt meter, earth tides, ocean tide loading.

\section{Introduction}

Discussions on the rigidity of the earth were initiated already 150 years ago by Kelvin 1863 (Michelson 1914). The Earth was recognised not only as an elastic body, but also as a plastic yielding "modulus of relaxation", termed by Maxwell. Plastic yielding is realised by the lag of the distortion relative to the forces producing it (Michelson 1914).

Michelson (1914), Gale (1914) and staff at Yerkes Observatory, Williams Bay, Wisconsin, USA carried out preliminary studies on the earth's rigidity using

1 Finnish Geospatial Research Institute, FGI, National Land Survey of Finland, Geodeetinrinne 2, 02430 Masala, Finland. E-mail: hannu.ruotsalainen@nls.fi east-west and north-south-oriented long water level tilt meters in autumn 1914. The water level tilt meters were installed at a 1.8-m-deep underground at the Yerkes Observatory. The tubes were $150 \mathrm{~m}$ long and half filled with water. Detailed descriptions are given in Michelson (1914) and in Gale (1914).

The amplitude ratio of measured tilt vs. calculated model tilt of an absolutely rigid earth gives the rate of deformation. The plastic yielding of the earth is observed from the retardation (lag) of the observed tilt phase to the tidal model tilt of absolutely rigid earth. The observed retardation of the earth tide signal must always be negative, because positive lag is meaningless (Michelson 1914). The mean amplitude ratio between observed east-west (EW) tilt to theoretical one was 0.710 and for north-south (NS) 0.523 . The phase lag of total earth tide tilt for EW was $-0.059 \mathrm{~h}$ and for NS was $+0.007 \mathrm{~h}$ in the 1914 tilt observations of Michelson (1914) and Gale (1914). ${ }^{1}$

A similar difference between amplitude ratios in EW and NS directions was also observed earlier by Hecker, and he interpreted the reason to be the difference in earth rigidity (Michelson 1914).

Love and Schweydar (Michelson 1914, p. 124) had the opinion that the difference is attributed to the effect of ocean tides, and it causes differences in ratios of observed amplitudes and phases to theoretical.

Michelson and Gale (M-G) continued studies after 1914 by experimenting further in 1916-1917, using the water level tilt meters presented above with an interferometric recording system developed by Michelson in 1910 (Michelson 1914). The recording

\footnotetext{
${ }^{1}$ A sign deviation exists in the observed phase of the northsouth and east-west tilt meter results between pages 111 and 122 in Michelson's original paper 1914.
}

The original version of this chapter was revised. The correction to this chapter is available at https://doi.org/10.1007/978-3-319-96277-1_23 
interferometers had direct internal absolute calibration. Figure 1 shows the principle of the recording setup (M-G 1919).

The refraction coefficient $\mu$ for water was 1.3408 with a wavelength of $435.8 \mathrm{~nm}$. The number of fringes $N$ caused by displaced water was calculated according to the formula

$$
N=\frac{2(\mu-1) d}{\lambda},
$$

where $\lambda$ was the wavelength of a mercury lamp light source with special arrangement and $\mathrm{d}$ was the displaced water level. One fringe corresponded to $1 / 1564 \mathrm{~mm}-639.4 \mathrm{~nm} /$ fringe. The tilt was estimated with $1 / 10$ of fringe, and according to the formula above, the tilt rate is 0.173 ms-of-arc (mas), which means 0.839 nanoradian (nrad) resolution for a 152.4-m-long instrument. Using the conversion formula above for the tilt rate/fringe, it is possible to estimate tilts and compare them, e.g. with the combined earth tide model and ocean tide loading (OTL) model tilts at Yerkes observatory. In Sect. 2, a comparison of $\mathrm{M}-\mathrm{G}$ observations with tilt predictions is given.

Kääriäinen (1979) constructed a water level tilt meter at the Finnish Geodetic Institute (FGI), which follows in principle the tube-pot technique developed by $\mathrm{M}-\mathrm{G}$ (1919). He presented dimensions and properties of the instrument, hydrodynamical condition of the water in the tube-pot system, the instrument's thermal expansion modelling on environmental temperature change, and orientation of the instrument at the station. The level interferometer (diagram in Fig. 2) was a typical off-axis Fizeau interferometric setup, and interference fringe recording was carried out by film camera. The shape of varying interference fringes on the film in this construction was different, because the interferometric setup by $\mathrm{M}-\mathrm{G}$ was completely different. A 177-m-long (EWWT) and 62-m-long (NSWT) water level tilt meter were built and installed in the Tytyri mine tunnel (geodynamic station Lohja2 of the FGI), in the vicinity of the city Lohja in southern Finland (Kääriäinen 1979; Kääriäinen and Ruotsalainen 1989). The location of the recording site is shown in Fig. 3. The reanalysed EWWT and NSWT results with OTL comparison are presented in Sect. 3.
The next step was a modern, redesigned, computer-controlled version of the laser interferometric water level tilt meter, installed at the same place as the NS-oriented instrument of the FGI (Ruotsalainen 2001). Construction details and earth tide analysis results with comparison to OTL models are described in Sect. 4.

\section{Predicting Tilt Observations for Michelson-Gale Experiments Using Combined Earth Tide and Ocean Tide Loading Model Tilt}

Using Agnew's (1997, 2012) ocean tide loading program, NLOADF, it is possible to determine harmonic ocean tide loading (OTL) amplitude and phase values for Yerkes Observatory $\left(42^{\circ} 34.2^{\prime} \mathrm{N}\right.$, $\left.88^{\circ} 33.4^{\prime} \mathrm{W}\right)$, e.g. using Schwiderski's ocean tide model. Figures 4, 5, 6 and 7 show the Schwiderski model's OTL vectors combined with the Wahr-Dehant-Zschau earth model tilt vectors (Schüller 2016) to predict harmonic model tilt observation in EW and NS directions. The green vectors are Wahr-DehantZschau model earth tide tilt (nrad) with diminishing factor $\gamma_{2}=1+\mathrm{k}-\mathrm{h}=0.6948$, using Love numbers $h=0.6032, k=0.2980$ (PREM, Agnew 2009) and $0.0^{\circ}$ phase, because Zschau (1978) argued that the observed earth tide phase lag is delayed only by $0.01^{\circ}-0.001^{\circ}$ to the theoretical model earth tide. Blue OTL vectors are subtracted from green earth tide model tilts, and red residual vectors are the prediction for tilt observation. They can be compared with $\mathrm{M}-\mathrm{G}$ observations, e.g. by converting tilt values (nrad) to fringe values by the conversion formula above. In the following figures, all the amplitudes are nrad and phases in degrees, phase lags are negative and local. Terminologies A cos (alpha) and A sin(alpha) in the figures follow the convention by Melchior (1983, p. 332) for indirect effects.

Figure 4 shows that in the NS direction, the diurnal band harmonic amplitudes are quite small. The $\mathrm{O} 1$ and $\mathrm{K} 1$ wave groups have less than a $3.2 \mathrm{nrad}$ tilt. The major energy NS direction is located in the semidiurnal wave band. The NS diurnal tilt harmonics have negative phase lags, but semidiurnal positive lags according to Schwiderski's OTL model. These explain the difficulties of amplitude and phase 


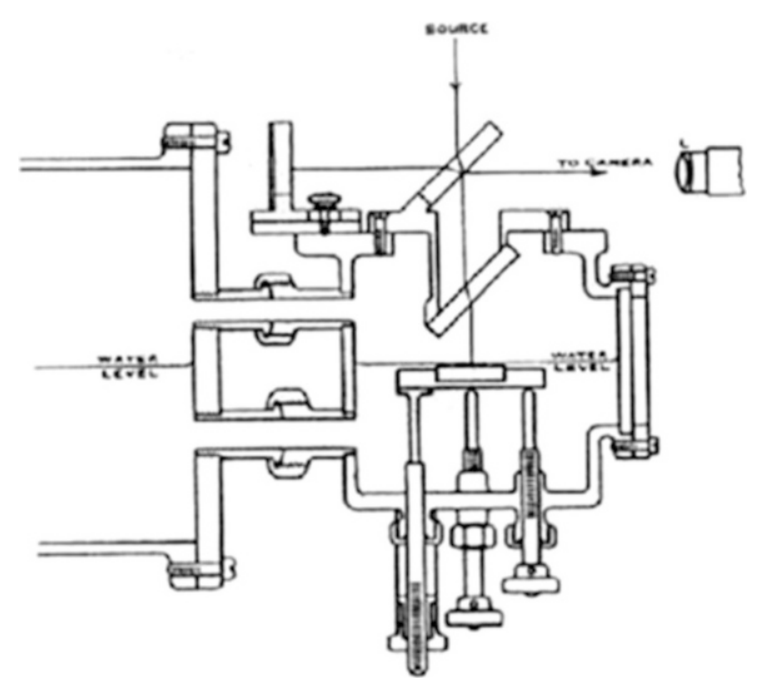

Figure 1

Principle of $\mathrm{M}-\mathrm{G}$ interferometric water level tilt meter. Picture from (Michelson and Gale 1919), (CAAS. Reproduced with permission

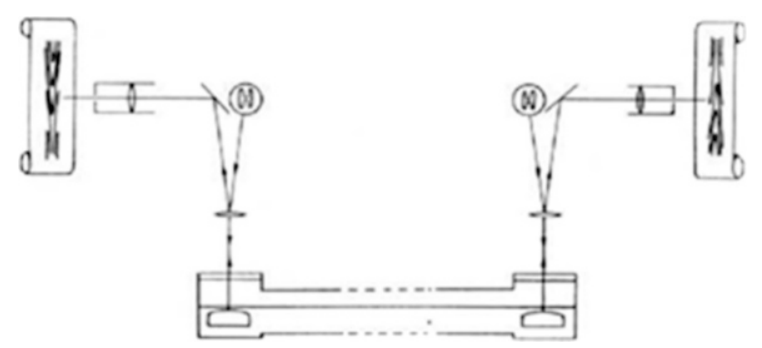

Figure 2

Operating principle of the old FGI water level tilt meter. Diagram from Kääriäinen (1979)

determinations 100 years ago. Love and Schweydar were right in their interpretation.

The only positive phase lag of predicted tilt in the EW direction exists in wave group N2. All others have negative lags.

In the EW direction, tilt phase lag for the K1 harmonic wave from Fig. 6 is as follows. The phase angle for $\mathrm{K} 1$ is

$$
\alpha=\arctan \left(\frac{A(\sin (\text { alpha }))}{A(\cos (\text { alpha }))} \approx-0.86^{\circ} .\right.
$$

The EW/K1 predicted phase lag is $-0.057 \mathrm{~h}$ in the time domain, and it is comparable to value $-0.059 \mathrm{~h}$, observed by Michelson (1914) and Gale (1914) as total EW tilt phase lag. The phase lag of the predicted NS/ M2 vector in Fig. 5 is $+0.015 \mathrm{~h}$, and the value Michelson and Gale got for the total NS tilt phase lag was $+0.007 \mathrm{~h}$. Michelson and Gale did not necessarily make an error in their calculation relating to earth tide tilt in 1914, because the positive phase lag in the NS direction complicates the comparison of the tilt observation and earth tide model tilt. Of course, all harmonic terms must be taken into account when determining the total diurnal or semidiurnal phase lags in each direction. By the least squares method, amplitude and phase values for diurnal and semidiurnal bands were determined again for interferometric setups by M-G (1919). The common diminishing of amplitude ratio in weighted mean is 0.690 and phase lag is $2^{\circ} 41^{\prime}$ for $\mathrm{NS}$ and $4^{\circ} 34^{\prime}$ for EW (the sign convention for lag is opposite than above) there.

\section{Reanalysis of the Earth Tide Tilt of the FGI Tilt Meters 1977-1993}

The resolution of tilt/fringe was determined according to the formula (Kääriäinen 1979),

$$
S=\frac{\lambda \times \rho \times 10^{3}}{2 \times n \times L},(\text { mas } / \text { fringe }),
$$

where $\lambda$ is the wavelength of light source, $\rho=206,265$ is the conversion factor from radians to arc-seconds, $n$ is the refraction coefficient of fluid and $L$ is the length of the tilt meter. Half of the length of the water level inside tube indicates the tilt rate and, therefore, the length, $L$, in the formula above must be $L / 2$. For sodium $(\mathrm{Na})$, the light-based fluid level interferometer tilt value is then 0.515 mas/fringe and for helium (He) light, 0.514 mas/fringe.

The EWWT- and NSWT-tilt meter data were reanalysed by ETERNA 3.4 Earth tide analysis program (Wenzel 1996) and the newest version ET34ANA-V52, developed by Schüller (2016). The OTL values based on Schwiderski (1980), TPXO7.0 (Egbert and Erofeeva 2002) and CSR4.0 (Eanes 1994) ocean tide models were determined using the NLOADF program by Agnew (1997). FES2004 (Lyard et al. 2006) OTL values were obtained using the OTL provided by Bos and Scherneck (2014) (http:// holt.oso.chalmers.se/loading/). The phase lags in the OTL provider is relative to Greenwich meridian and lags positive. They must be converted from Greenwich meridian to local with sign convention using the formula by Agnew (2009). 


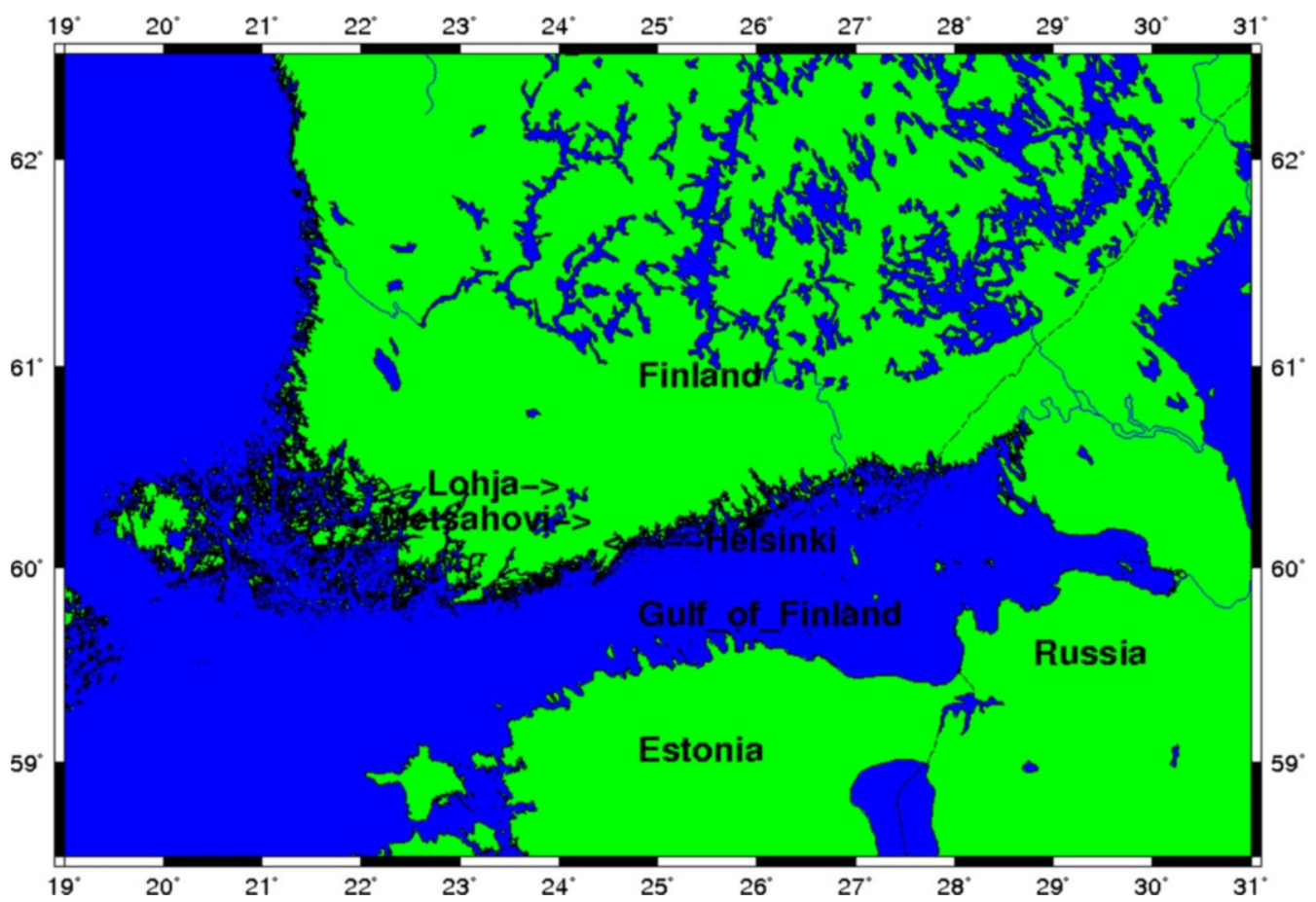

Figure 3

Location observation site Lohja in southern Finland

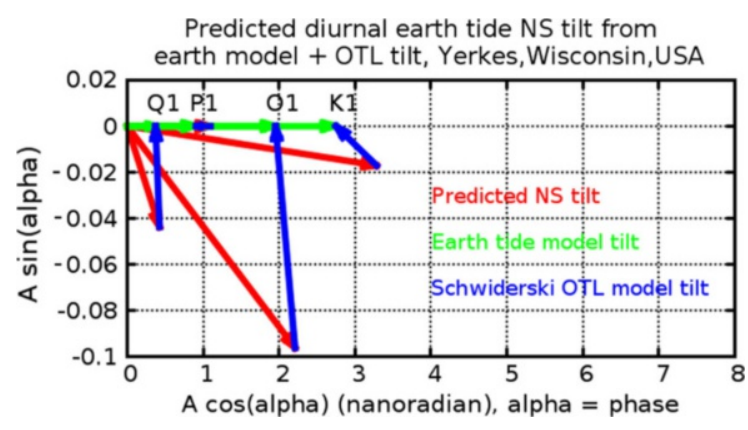

Figure 4

Predicted (red) earth tide tilt from OTL (blue) and earth tide model (green) in diurnal band in NS direction

The EW scale of diurnal CSR4.0 OTL model is three times larger than the theoretically predicted earth tide. In the diurnal band, Schwiderski's OTL amplitudes and phases are too small. The main reason for the wave group $\mathrm{K} 1$ phase deviation is the wellknown core-mantle resonance (Fig. 8).

In the semidiurnal band in the EW direction, CSR4.0 amplitudes and phases excluding the N2 wave group fit better than Schwiderski and TPXO7.0.

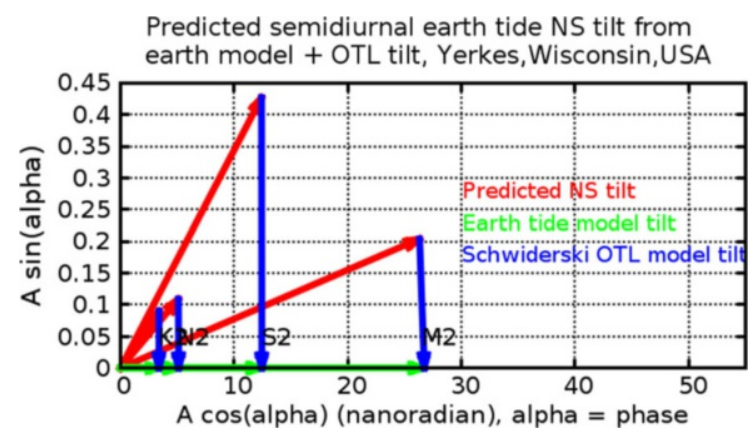

Figure 5

Predicted (red) earth tide tilt from OTL (blue) and earth tide model (green) in semidiurnal band in NS direction

The FES2004 model has the most deviating phases and amplitudes there (Fig. 9).

In the NS orientation, all OTL models deviate from observations, and the reason can be partly the improperly modelled Baltic Sea loading and partly the Norwegian Sea/Arctic Sea OTL modelling.

The OTL values in the diurnal frequency band in Q1, P1 and O1 wave groups have amplitude values in fraction of nanoradian in the Schwiderski, CSR4.0 


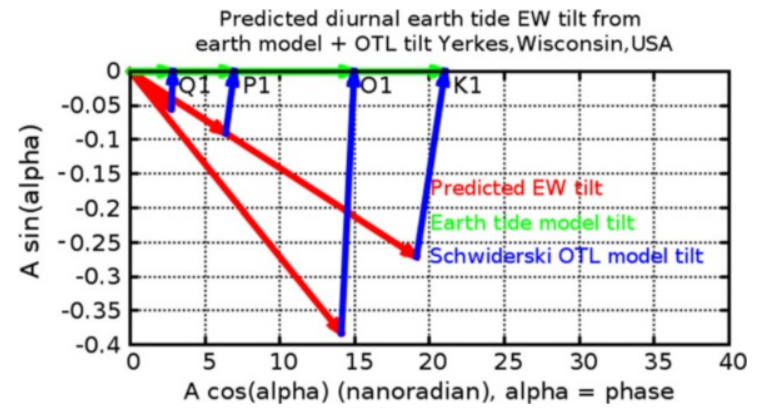

Figure 6

Predicted (red) earth tide tilt from OTL (blue) and earth tide model (green) in diurnal band in EW direction

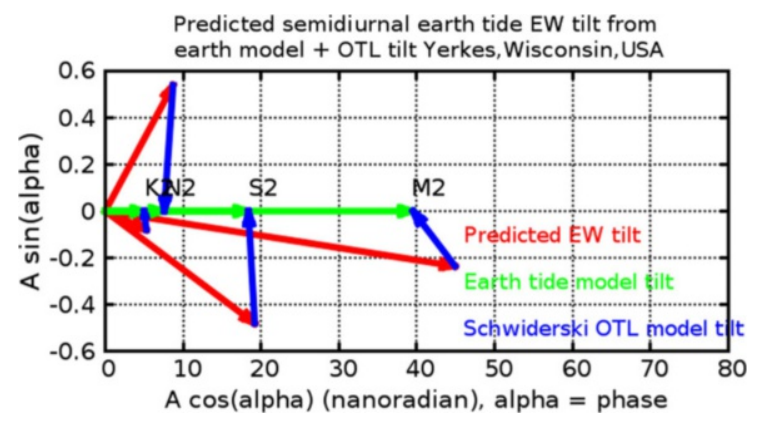

Figure 7

Predicted earth tide tilt from OTL and earth tide model in semidiurnal band EW direction

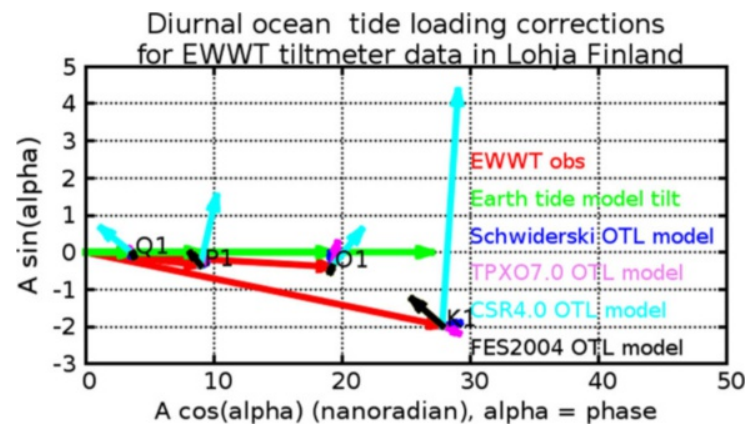

Figure 8

Observed earth tide tilt of EWWT with OTL models in the diurnal band in the EW direction

and TPXO7.0 models. In the case of FES2004, the values are too big compared to others in the same wave groups. The $\mathrm{K} 1$ wave group amplitudes are larger, but only Schwiderski and CSR4.0 show the phase angle in the right direction [the $\mathrm{K} 1$ vector in the CSR4.0 model for NSWT in Ruotsalainen et al. (2015) contained a combined TPXO7.0 model for northern latitudes; therefore, it is larger there]. The

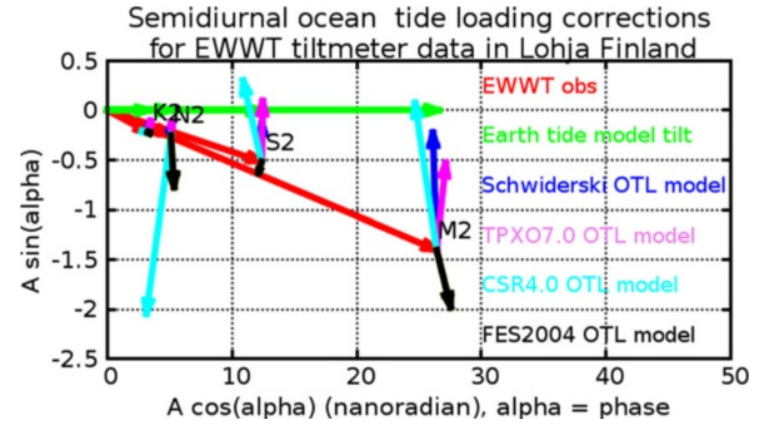

Figure 9

Observed earth tide tilt of EWWT with OTL models in semidiurnal band in the EW direction

larger phase deviation from the theoretical earth tide model in the case of $\mathrm{K} 1$ is caused again by coremantle resonance (Fig. 10).

In the semidiurnal band NS direction, nearly all models are deviating from the preferable phase. The Schwiderski model fits in the case of N2 and S2 (Fig. 11).

\section{Modernisation of the FGI Water Level Tilt Meter}

Mechanics, automation and a higher tilt resolution were the reasons for modernisation of fluid level sensing of the interferometric water level tilt meter of the FGI. The HeNe laser, digital camera and automated interference phase interpretation were used for modernisation (Ruotsalainen 2001). Some details were taken into account from innovations of the former tilt meter design of the FGI. In the new design, special stainless steel is used in the tube and pot constructions to avoid corrosion in a hostile mine

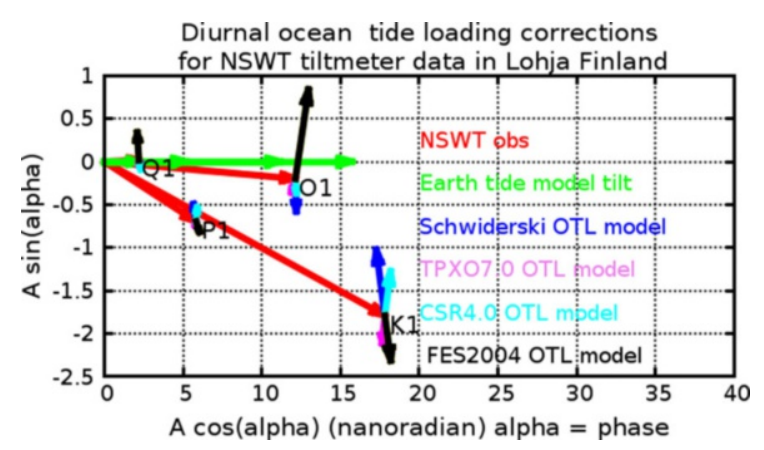

Figure 10

Observed earth tide tilt of NSWT with OTL models in diurnal band in the NS direction 


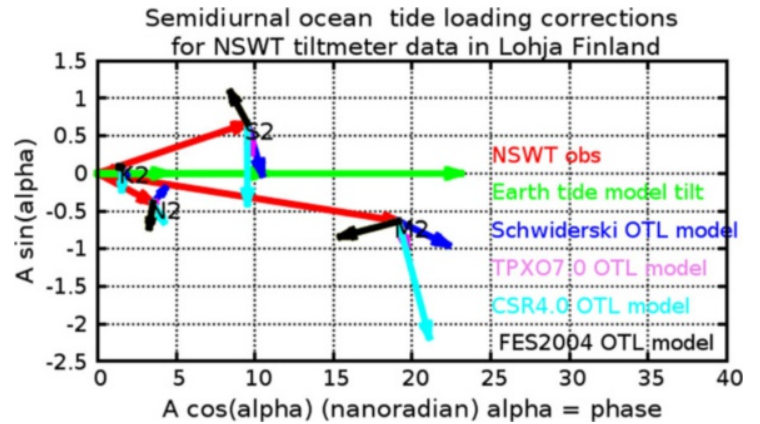

Figure 11

Observed earth tide tilt of NSWT with OTL models in semidiurnal band in the NS direction

environment. Fizeau-Kukkamäki interferometer principle (see Fig. 12) is used for a level sensing laser interferometer together with fibre optics.

Thorlabs HGR020 HeNe laser $\left(\lambda_{\text {vacuum }}=543.0\right.$ $\mathrm{nm}$ ) is used as a light source for interferometer. Collimation of the beam is carried out by a telescopetype collimator connected to an optical fibre, as shown in Fig. 13. Basler A602f CMOS cameras are used for the recording of interference fringes with a sampling rate of $15 \mathrm{~Hz}$. In Fig. 13, the Basler A602f camera system is located to the left of the end pot system, sealed against humidity inside a plastic box (Ruotsalainen et al. 2015).

\section{Recordings and Analysis of the Earth Tide}

The tilt resolution of the modern laser interferometer level sensing water level tilt meter (NSiWT) in Lohja2 is

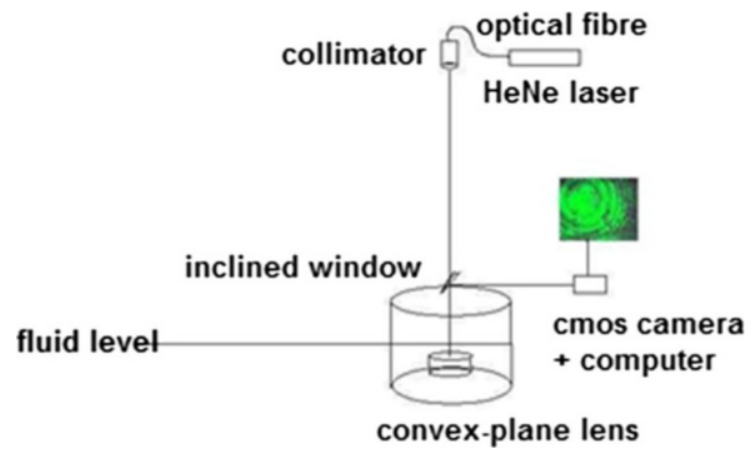

Figure 12

Principle of Fizeau-Kukkamäki fluid level interferometer

$$
S=\frac{\lambda_{\text {air }}}{n \times L},(\text { nrad } / \text { fringe }),
$$

where $\lambda_{\text {air }}$ is the wavelength of laser light (nanometres) and $n$ is the refraction coefficient of water in physical conditions at the observation site. The wavelength value in the formula for laser light in the air is $\lambda_{\text {air }}=542.8 \mathrm{~nm}$ in the nominal physical condition of the station, when variations of the local air pressure, temperature and humidity are not yet corrected. These local variations cause a less than $10 \mathrm{pm}$ variation in level sensing. The refraction coefficient of water is $n=1.333$, determined by optical refraction observations. The length of the tube, $L=50.40 \mathrm{~m}$, is measured with steel tape. The tilt resolution is then $8.0794 \mathrm{nrad} /$ fringe and, for $1 / 100$ of fringe $\quad(2.03 \mathrm{~nm}$ level sensing $), \quad 0.077 \mathrm{nrad}$ (0.016 mas).

The example tilt recording of the NSiWT is given in Fig. 14. The red curve is the tilt recording, and the green curve is the theoretical tidal model tilt with amplitude factor 0.6948 (PREM, Agnew 2009) and zero phase (Heikkinen 1978). The observed tilt deviation from theoretical earth tide tilt is mainly caused by ocean tide loading, the Baltic Sea loading and atmospheric loading (Ruotsalainen et al. 2015, p. 160).

The NSiWT tilt meter data were also analysed by the ETERNA 3.4 Earth tide analysis program (Wenzel 1996) and its version ET34-ANA-V52, developed by Schüller (2016). Figures 15 and 16 show the analysis results for the main tidal harmonic wave groups.

Very small differences exist in earth tide analysis results between the old NSWT and new NSiWT water level tilt meters. The largest deviation between amplitude factors is 0.0315 in the $\mathrm{O} 1$ wave group, and other deviations are considerably smaller. In the tidal phase, the largest deviation is $6.10^{\circ}$ in wave group Q1. In other wave group phases, they are within $\pm 2.15^{\circ}$.

The deviation in phase of the wave group Q1 between instruments can be explained by the loading effect of the seiche oscillation phenomenon of the Baltic Sea. The oscillation of $26.2 \mathrm{~h}$ in the Gulf of Finland was determined by Lisitzin (1959), and this non-tidal period is harmfully located inside wave 


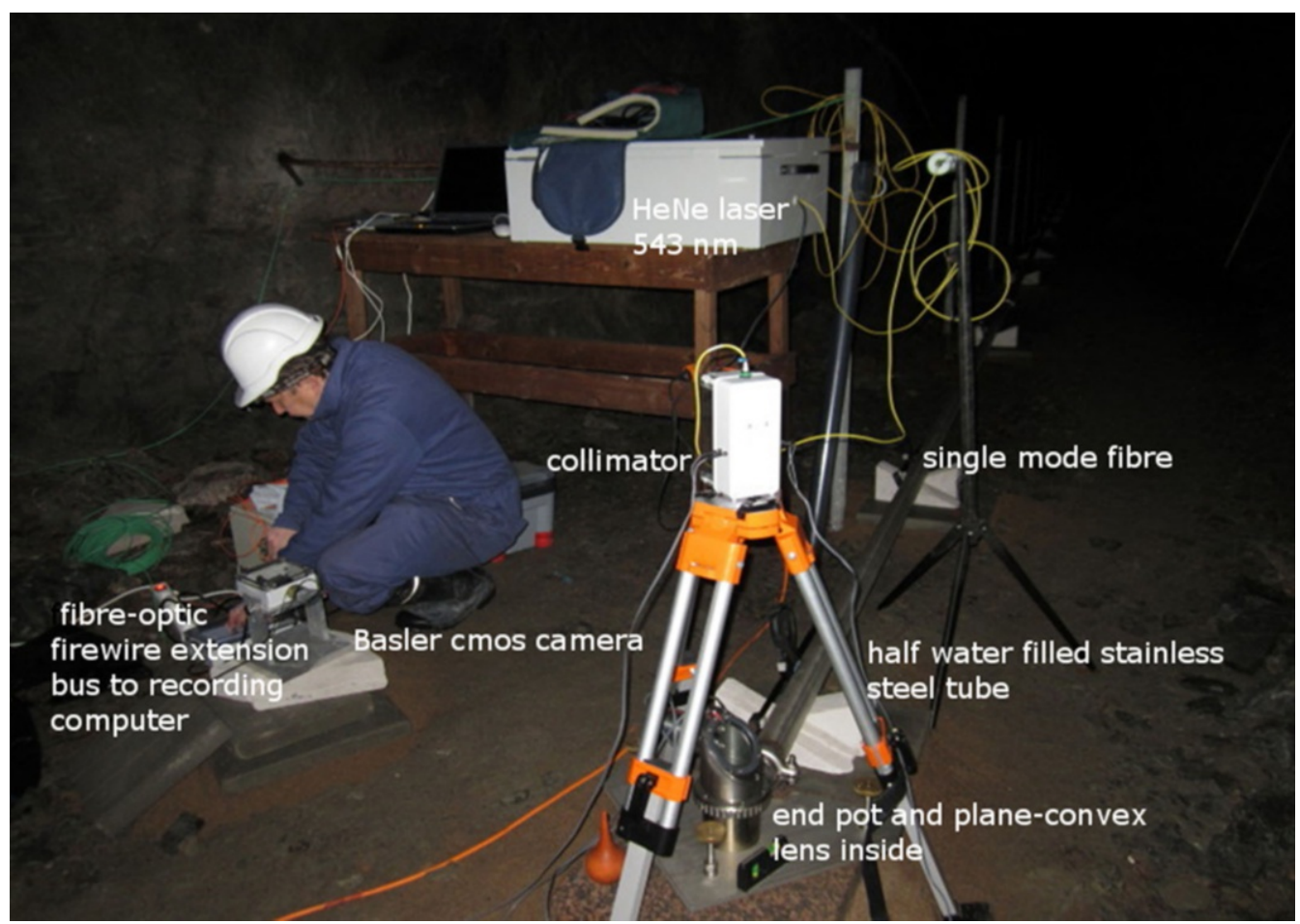

Figure 13

End pot-tube system, collimator connected with fibre to HeNe laser and Basler A602F CMOS camera system on the floor of the Tytyri mine at Lohja2 geodynamics station. Photo: M. Portin

group Q1 in the tidal frequency band. The phases of seiche oscillations frequencies are mainly wind generated; therefore, they strongly disturb both the earth tide tilt and the Baltic Sea tidal wave signals (Witting 1911) and their loading tilt at Lohja (Ruotsalainen et al. 2015, p. 160).

In the semidiurnal band, both in NSWT and NSiWT, the M2 amplitude factor diminishing to 0.56 can be recognised and none of the OTL models can correct the tilt to fit the earth tide model tilt. Amplitudes are of a preferable size, but the phases are not fitting? The Baltic Sea and atmospheric tidal loading harmonic presentations need to be taken into more careful consideration and combined for modelling.

The broad band of other geophysical phenomena (Ruotsalainen 2012) has been recorded since 2008, when the 50.4-m-long NSiWT instrument was set up as operational in the Lohja2 geodynamic station. These include Baltic Sea non-tidal loading and atmospheric loading (Ruotsalainen et al. 2015), free oscillations of the earth after great earthquakes (Ruotsalainen 2012), microseism and secular tilt recordings.

\section{Conclusions}

The semidiurnal earth tide tilt predictions in the NS direction using combined earth model tilt and Schwiderski OTL model tilt show positive lags and predicted diurnal amplitudes with negative lags smaller than 3 nrad in the NS direction for Yerkes observatory. The semidiurnal band in the NS tilt recording has a leading role, instead of diurnal, and this explains the uncertainty in the interpretation of the earth tide analysis of the Yerkes tilt observations 100 year ago.

The earth tide analysis of the tilt recordings between the old NSWT and new NSiWT tilt meters of the FGI has no significant differences. However, there are differences in ocean tide loading models compared to the tilt observations in the Lohja2 


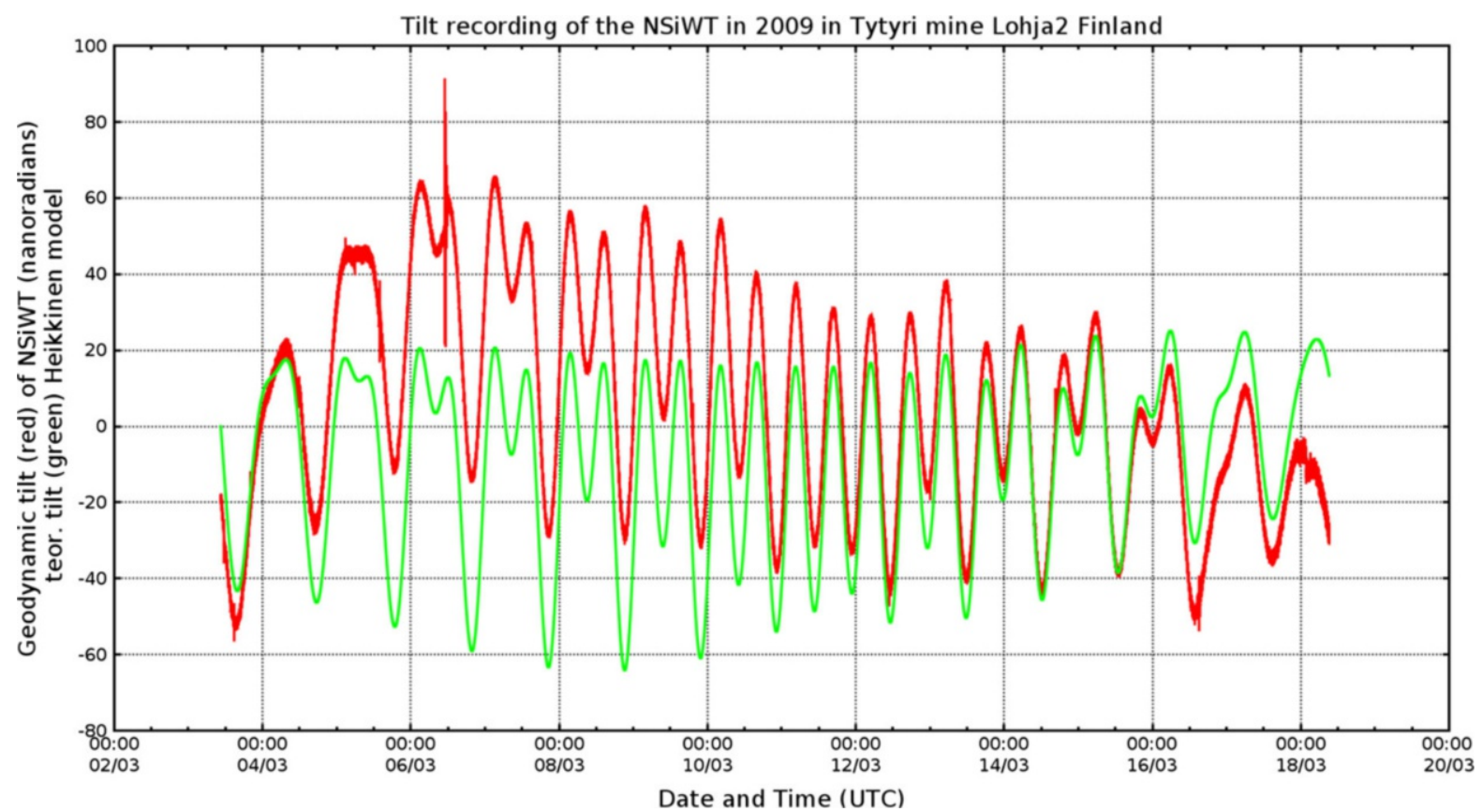

Figure 14

Tilt recording (red) of the new interferometric tilt meter of the FGI and theoretical tilt (nrad), (Heikkinen 1978)

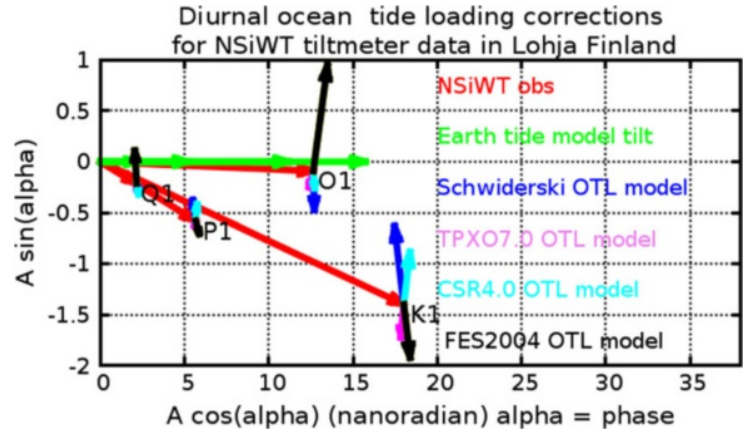

Figure 15

Observed earth tide tilt of NSiWT with OTL models in diurnal band in the NS direction

station. The best OTLs fit the earth tide model tilt in the semidiurnal EWWT tilt observation. The coremantle resonances exist clearly in all three observation data sets.

OTL models do not explain the amplitude diminishing ( 0.6948 to $>0.56$ ) of M2 wave groups in NSWT and NSiWT tilt meter data in the NS direction. Baltic Sea and atmospheric loading harmonic modellings are the next steps in giving information on the deviating features of OTL models.

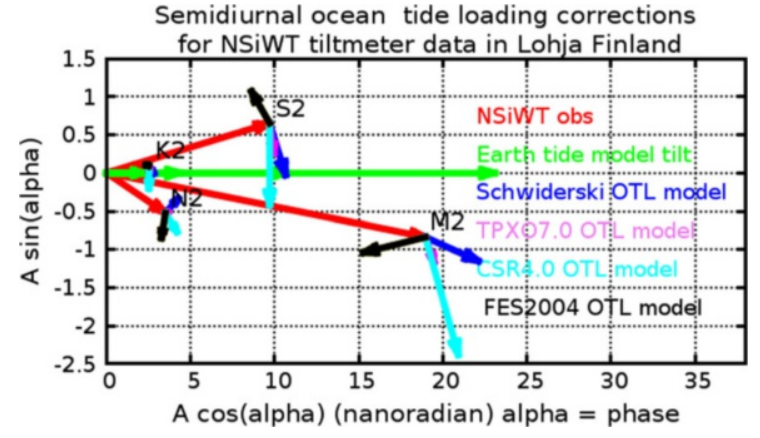

Figure 16

Observed earth tide tilt of NSiWT with OTL models in semidiurnal band in the NS direction

A modern NSiWT fluid level tilt meter is suitable for geodynamic and geophysical studies with an absolute scale.

\section{Acknowledgements}

Agnew's SPOTL program was used for computing ocean tidal loading. The ocean tide loading provider, developed by Bos and Scherneck, was also used for 
determination of OTL tilt. The modern version of the program ET34-ANA-V52 of the original ETERNA 3.4 program by Wenzel, developed further by Schüller, was used for the earth tide analysis. All of the above programs and data obtained are kindly acknowledged. Thanks go to two anonymous referees on their critical comments of the manuscript. The permission to reproduce material from The Astrophysical Journal, volumes 39 and 50, on behalf of the AAS by IOP Publishing, is kindly acknowledged.

Open Access This article is distributed under the terms of the Creative Commons Attribution 4.0 International License (http:// creativecommons.org/licenses/by/4.0/), which permits unrestricted use, distribution, and reproduction in any medium, provided you give appropriate credit to the original author(s) and the source, provide a link to the Creative Commons license, and indicate if changes were made.

\section{REFERENCES}

Agnew, D. C. (1997). NLOADF: A program for computing oceantide loading. Journal of Geophysical Research, 102, 5109-5110.

Agnew, D. C. (2009). Earth tides. In G. Schubert \& T. Herring (Eds.), Geodesy. Oxford: Elsevier.

Agnew D. C. (2012). SPOTL: Some programs for ocean-tide loading, SIO Techn. Rep., Scripps Institution of Oceanography. http://escholarship.org/uc/item/954322pg.

Bos, M. S., Scherneck, H. G. (2014). Free ocean tide loading provider. Onsala Space Observatory, Chalmers University of Technology, Gothenburg, Sweden. http://holt.oso.chalmers.se/ loading/.

Eanes, R. J. (1994). Diurnal and semidiurnal tides from TOPEX/ POSEIDON altimetry. Eos Transactions American Geophysical Union, 75(16), 108.

Egbert, G. D., \& Erofeeva, L. (2002). Efficient inverse modeling of barotropic ocean tides. Journal of Atmospheric and Oceanic Technology, 19, 183-204.

Gale, H. (1914). On an experimental determination of the earth's elastic properties. Science New Series, 39(1017), 927-933.
Heikkinen, M. (1978). On the tide generating forces. Publication of the Finnish Geodetic Institute, No. 85, Helsinki.

Kääriäinen, J. (1979). Observing the earth tides with a long water tube tilt meter. Annales Academiae Scientiarum Fennicae A VI Physica, 424.

Kääriäinen, J., Ruotsalainen, H. (1989). Tilt measurements in the underground laboratory Lohja 2, Finland in 1977-1988. Publication of the Finnish Geodetic Institute, No. 110, Helsinki.

Lisitzin, E. (1959). Uninodal seiches in the oscillation system Baltic proper, Gulf of Finland. Tellus, 4, 459-466.

Lyard, L., Lefevre, L., Letellier, T., \& Francis, O. (2006). Modelling the global ocean tides: Insights from FES2004. Ocean Dynamics, 56, 394-415.

Melchior, P. (1983). The tides of the planet earth. Oxford: Pergamon Press.

Michelson, A. A. (1914). Preliminary results of measurement of the rigidity of the earth. Astrophysical Journal, 39, 105-128.

Michelson, A. A., \& Gale, H. (1919). The rigidity of the earth. Astrophysical Journal, 50, 330-345.

Ruotsalainen, H. (2001). Modernizing the Finnish long water-tube tilt meter. Journal of the Geodetic Society of Japan, 47(1), 28-33.

Ruotsalainen, H. (2012). Broad band of geophysical signals recorded with an interferometrical tilt meter in Lohja, Finland. Geophysical Research Abstracts Vol. 14, EGU2012-9827, 2012 EGU General Assembly 2012.

Ruotsalainen, H., Nordman, M., Virtanen, J., \& Virtanen, H. (2015). Ocean tide, Baltic Sea and atmospheric loading model tilt comparisons with interferometric geodynamic tilt observationcase study at Lohja2 geodynamic station, southern Finland. Journal of Geodetic Science, 5(1), 2081-9943. doi:10.1515/jogs2015-0015. (ISSN (online)).

Schüller, K. (2016). User's guide ET34-ANA-V5.2, Installation Guide ETERNA34-ANA-V5.2, Surin.

Schwiderski, E. W. (1980). On charting global ocean tides. Reviews of Geophysics and Space Physics, 18(1), 243-268.

Wenzel, H. G. (1996). The nanogal software: Earth tide data processing package Eterna 3.30. Bulletin d'Information des Marées Terrestres, 124, 9425-9439.

Witting, R. J. (1911). Tidvattnen i Östersjön och Finska viken. In Fennia 29 (p. 84 ). Helsinki: Simelius (in Swedish).

Zschau, J. (1978). Tidal friction in the solid earth: Loading tides versus body tides. In P. Brosche \& J. Sündermann (Eds.), Tidal friction and the earth's rotation. New York: Springer. 